\title{
The patient perspective: arthritis care provided by Advanced Clinician Practitioner in Arthritis Care program-trained clinicians
}

This article was published in the following Dove Press journal:

Open Access Rheumatology: Research and Reviews

19 August 2015

Number of times this article has been viewed

\section{Kelly Warmington' \\ Carol A Kennedy ${ }^{2}$ \\ Katie Lundon ${ }^{3}$ \\ Leslie J Soever ${ }^{4}$ \\ Sydney C Brooks ${ }^{5}$ \\ Laura A Passalent ${ }^{6}$ \\ Rachel Shupak ${ }^{7}$ \\ Rayfel Schneider ${ }^{8}$}

'Learning Institute, Hospital for Sick Children, ${ }^{2}$ Musculoskeletal Health and Outcomes Research, St Michael's Hospital, ${ }^{3}$ Continuing Professional Development, Faculty of Medicine, University of Toronto, ${ }^{4}$ University Health Network, ${ }^{5}$ Ontario Division, Arthritis Society, ${ }^{6}$ Toronto Western Hospital, ${ }^{7}$ Division of Rheumatology, St Michael's Hospital, ${ }^{8}$ Division of Rheumatology, Hospital for Sick Children, University of Toronto, Toronto, ON, Canada
Correspondence: Carol A Kennedy Musculoskeletal Health and Outcomes Research, St Michael's Hospital, 30 Bond Street, Toronto, ON M5B IW8, Canada Tel +I 4168646060 ext 77035

$\mathrm{Fax}+\mathrm{I} 4168645003$

Email Kennedyca@smh.ca
Objective: To assess patient satisfaction with the arthritis care services provided by graduates of the Advanced Clinician Practitioner in Arthritis Care (ACPAC) program.

Materials and methods: This was a cross-sectional evaluation using a self-report questionnaire for data collection. Participants completed the Patient-Doctor Interaction Scale, modified to capture patient-practitioner interactions. Participants completed selected items from the Group Health Association of America's Consumer Satisfaction Survey, and items capturing quality of care, appropriateness of wait times, and a comparison of extended-role practitioner (ERP) services with previously received arthritis care.

Results: A total of 325 patients seen by 27 ERPs from 15 institutions completed the questionnaire. Respondents were primarily adults (85\%), female (72\%), and living in urban areas $(79 \%)$. The mean age of participants was 54 years (range 3-92 years), and 51\% were not working. Patients with inflammatory (51\%) and noninflammatory conditions (31\%) were represented. Mean (standard deviation) Patient-Practitioner Interaction Scale subscale scores ranged from 4.50 (0.60) to $4.63(0.48)$ ( 1 to 5 [greater satisfaction]). Overall satisfaction with the quality of care was high (4.39 [0.77]), as was satisfaction with wait times (referral to appointment, 4.27 [0.86]; in clinic, 4.24 [0.91]). Ninety-eight percent of respondents felt the arthritis care they received was comparable to or better than that previously received from other health care professionals.

Conclusion: Patients were very satisfied with and amenable to arthritis care provided by graduates of the ACPAC program. Our findings provide early support for the deployment and integration of ACPAC ERPs into the Ontario health care system and should inform future evaluation at the patient level.

Keywords: arthritis, physical therapists, occupational therapy, education, continuing, patient satisfaction

\section{Introduction}

The past 15 years have seen an evolution in the provision of arthritis care for a variety of reasons. Increased demands in the aging population, physician shortages, and stretched health care funding have catalyzed the development of new extended-care clinical roles to meet the need for arthritis care professionals. ${ }^{1,2}$ With the introduction of novel roles, it is important to capture the patients' perspective on the care they are receiving. In addition, patients are valued members of circles of care, and it is critical to integrate their voices into decision-making processes where possible. Patients' satisfaction with their care is known to influence health-related behaviors, ${ }^{3}$ such as compliance, maintenance of patient-health care provider relationships, ${ }^{4,5}$ and communication of important information, ${ }^{4}$ as well as treatment outcomes. ${ }^{6-9}$ 
In the past, individual extended roles have been developed on an as-needed basis, in order to meet the needs of a specific population or institution. Generally, the skills and competencies required of the clinician are developed over time through mentorship or in-service experience. In contrast, the Advanced Clinician Practitioner in Arthritis Care (ACPAC) program was formally developed in recognition of Ontario's need to enlarge the pool of human health resources capable of providing specialized arthritis care. A collaboration between St Michael's Hospital and the Hospital for Sick Children in Toronto, the ACPAC program addresses this educational gap in postlicensure training and provides standardized knowledge and skills in order to train competent advanced practice, or extended-role practitioners (ERPs). It is a certificate-based program accredited by the Faculty of Medicine's Continuing Professional Development Office at the University of Toronto.

The ACPAC program was developed in 2005 in response to 1 ) the progressive decline in the number of arthritis care specialists resulting in inappropriate wait times for care, ${ }^{10}$ and 2) a well-recognized need for an interdisciplinary approach to manage patients with osteoarthritis, inflammatory arthritis, and other musculoskeletal (MSK) disorders more efficiently. ${ }^{1,2}$ Between 2005 and 2009, 30 experienced physical therapists and occupational therapists graduated from the ACPAC program. Program graduates are trained to practice to the full scope of their profession, and are, under medical directives, able to carry out such activities as ordering X-rays and blood tests, and in a few cases performing joint injections and modifying prescription-medication dosages. As these ERPs integrate into the Ontario health care system, ${ }^{11-13}$ it becomes important to capture the patients' perspective on the care they are receiving.

The aim of the ACPAC program is to prepare experienced physical therapists and occupational therapists, and more recently nurses, for extended-practice roles and to support them in the development and implementation of innovative models of arthritis care across various clinical settings. The program focuses on the assessment, diagnosis, triage, and independent but collaborative management of selected MSK and arthritis-related disorders. The ACPAC program is a learner-centered, academic, and experiential learning opportunity facilitated by an interprofessional faculty. The program integrates theory and practice and employs a blended-learning approach, including online, classroom-based, case-based, and clinical education, over 10 months. Learners engage in a minimum of 480 hours of training and are rigorously evaluated.
The present study is one component of a system-level evaluation assessing the impact of ACPAC program graduates at the patient, institution, and system levels. The systemlevel evaluation framework is based on the adapted "balanced scorecard" approach" ${ }^{14}$ utilized in the "Hospital Report: Rehabilitation" series. ${ }^{15}$ This study specifically focused on the patients' perspectives, eliciting their satisfaction with different elements of their care.

This study is novel in that we have evaluated patient satisfaction among a broad group of patients treated by a large number of uniquely trained clinicians who work in very diverse clinical settings (varied geographical area, patient population, and model of care) and who have completed a formal postlicensure competence-driven interprofessional education program.

\section{Materials and methods \\ Patient population}

Consecutive patients seen by ACPAC program-trained therapists were asked to complete the patient-satisfaction survey at a single time point. Participants had to exhibit MSK signs or symptoms or have a clinical MSK diagnosis. Adults (18 years of age or older) and children (17 years of age or younger) were included in the study population. Parents determined whether they or their child should complete the survey. Parents completing the survey were asked to do so from their child's perspective. Participants (or proxies) had to be able to complete the questionnaire in English, and they had to be seeing the clinician in a face-to-face visit.

\section{ACPAC program-trained ERPs}

ACPAC program-trained ERPs practice in a variety of clinical settings across Ontario, working with orthopedic, inflammatory, adult, pediatric, urban, and rural and community-based populations. Passalent et al described more fully the roles of practicing ERPs, as well as their system integration and clinical utilization. ${ }^{16}$ At the time of this study, all ERPs were at least 1 year postgraduation, and 27 of 30 graduates were practicing in 15 institutions across Ontario. Three were on leaves of absence.

\section{Recruitment}

Ethical approval for this study was acquired from all institutions in which the ERPs practice. Based on estimated patient volumes, ERPs were sent up to a maximum of 75 questionnaire packages (range 5-75). Questionnaire packages included an introductory letter inviting patient participation, the patient-satisfaction survey, and a postage-paid 
return envelope. Consent to participate was implied in the completion and mailing of the survey.

A clinic administrator, or in a few cases the ERP, introduced the study to each patient. Patients were asked to choose whether or not to participate after leaving the clinic, and they were informed in the introductory letter that their individual responses would not be shared with their ERP. Patients were encouraged not to tell their ERP whether they had chosen to participate. If participants opted not to participate, they were asked to discard the questionnaire package after leaving the clinic.

Surveys were identified by a study ID number. This number identified the therapist and institution, and was unique to each patient but not linked to identifiable patient information. Following 8 weeks of recruitment, ERPs reported how many surveys they had left over, such that we could calculate the number of surveys distributed to patients. Surveys were accepted by the study coordinator for 3 months following the end of recruitment.

\section{Survey content}

Hudak and Wright detailed the various characteristics of patientsatisfaction measures. They outlined methodological attributes related to question format and administration (eg, open-ended versus closed-ended, or self- versus interviewer-administered), as well as content axes (eg, satisfaction with a care versus treatment outcome, or generic versus disease-specific measures) onto which various measures can be mapped. ${ }^{17}$ They noted that the conclusions that can be drawn about satisfaction will vary depending on the characteristics of the measures used, and suggested that appropriate consideration be given to the intended use of the study findings. The authors recommended the use of complementary measures that include a combination of validated and context- or population-specific items.

The nature and objectives of our study determined the methodology and content of the questionnaire. Methodologically, this is a self-administered survey focusing on patients' perceptions of the care they have received. The survey includes both open and closed-ended questions, and the response format of quantitative items was standardized across measures where possible. The content of the survey focuses on care, as opposed to treatment outcomes, utilizing generic measures to assess the patient's actual care experience. The questionnaire includes both global and multidimensional measures.

\section{Patient satisfaction}

Our primary outcome was assessed using the eleven-item Patient-Doctor Interaction Scale, ${ }^{18-20}$ modified to reflect the
Patient-Practitioner Interaction Scale (PPIS). For each item, the term "doctor" was changed to "advanced practitioner". Each item is a statement describing the occurrence of various elements of a patient-clinician interaction, with higher levels of agreement indicating a more positive experience. Response options ranged from 1 (strongly disagree) to 5 (strongly agree). The PPIS is comprised of three subscales: providing information (two items), rapport (six items), and communication (three items), which are reported independently. Subscale scores are the mean of completed items and range from 1 to 5 , with 5 indicating greater satisfaction. Subscale scores were not calculated for those subscales with missing responses, as advised by the developers.

Participants were also asked to complete selected items from the Group Health Association of America's Consumer Satisfaction Survey (GHAA CSS). ${ }^{21}$ Six items were chosen from the GHAA CSS that captured aspects of care not addressed in the PPIS. These included history taking, explanation of the results of investigations, the opportunity to discuss questions, satisfaction with answers to questions, the helpfulness of recommendations/advice provided, and the usefulness of educational materials provided. Response options ranged from 1 (strongly disagree) to 5 (strongly agree), with higher levels of agreement indicating a more positive experience.

In addition, two items were developed that addressed satisfaction with the physical examination and the explanation of the patient's diagnosis. Again, response options ranged from 1 (strongly disagree) to 5 (strongly agree), with 5 indicating a more positive experience.

Individual items assessing satisfaction with additional aspects of care included the following: 1) acceptability of wait time since referral and in clinic at time of visit (two items), ${ }^{22}$ 2) a comparison of the arthritis care received from the ACPAC program-trained clinician with that previously received from other health care professionals (one item), 3) the patient's perception that their ERP was the most appropriate clinician to be seeing them (one item), and 4) overall satisfaction with the quality and coordination of care provided (two items). ${ }^{15}$

\section{Other outcomes}

In addition to patient satisfaction, the survey included an 11 -point numerical rating scale for pain (points at 0 and multiples of 10,0 to 100 [pain as bad as can be]) and two 5 -point numerical rating scales assessing function and overall health (1 to 5 [excellent]). ${ }^{23}$ In an open-ended question, 
participants were asked to include any additional feedback under the headings "Things we are doing well" and "Areas for improvement".

\section{Demographics}

The demographics section of the questionnaire collected data regarding visit type (initial or follow-up), diagnosis, and disease duration, as well as year of birth, sex, level of education, work status, and urban/rural status using the first three digits of the participant's postal code.

\section{Data analysis}

Survey data were entered into an Access 2002 (version 10) database by the study coordinator. Validity checks were in place for each variable. Quantitative data were exported into SAS (version 9.1) for analysis. Univariate statistics were used to describe the study population (Table 1). PPIS subscores were calculated in SAS according to the developer's specifications. ${ }^{18}$ All secondary outcomes are reported at the item level. In addition, participants' answers to open-ended questions were reviewed and common themes were extracted. Recurrent topics were grouped into broad categories. Reliability (internal consistency) for the PPIS was calculated using Cronbach's $\alpha$.

\section{Results}

A total of 695 surveys were distributed to patients at 15 institutions; 325 (46.8\%) were returned to the study coordinator. Percentage returns for individual therapists ranged from $8.0 \%$ to $67.5 \%$ (mean $44.8 \%$ ) and for institutions from $27.0 \%$ to $75.8 \%$ (mean $49.8 \%$ ).

\section{Participant characteristics}

The mean age of respondents was 54 years (range 3-92 years); $72.4 \%$ were female and $78.9 \%$ lived in urban areas. Most (67.1\%) had completed high school or beyond, and just over half ( $\mathrm{n}=166,51.1 \%)$ were not working, while 102 (31.4\%) were working.

Just over half of the respondents had been diagnosed with an inflammatory condition $(n=165,50.8 \%), 102$ $(31.4 \%)$ reported having noninflammatory conditions, and the remaining $42(12.9 \%)$ were unsure of their diagnosis. A detailed breakdown of participant diagnoses is presented in Table 1. Mean symptom duration was 9.70 years. Respondents reported moderate pain, function, and overall health. Similar numbers of respondents were seeing an ACPAC program-trained therapist for an
Table I Characteristics of participants

\begin{tabular}{|c|c|}
\hline & $\begin{array}{l}\text { Entire population } \\
\mathrm{n}=325\end{array}$ \\
\hline \multicolumn{2}{|l|}{ Demographic characteristics of participants } \\
\hline Age (years), mean (range) & $54(3-92)$ \\
\hline Adult, $\mathrm{n}(\%)$ & $265(8 I .5)$ \\
\hline Pediatric, n (\%) & $53(16.3)$ \\
\hline Female, n (\%) & $233(72.4)$ \\
\hline \multicolumn{2}{|l|}{ Education, n (\%) } \\
\hline Elementary school (some or completed) & $75(23.5)$ \\
\hline Completed high school or higher & $214(67.1)$ \\
\hline Other/not applicable (includes not yet in school) & $30(9.4)$ \\
\hline \multicolumn{2}{|l|}{ Work status, ${ }^{\mathrm{a}} \mathrm{n}(\%)$} \\
\hline Working for pay (full- or part-time) & $102(31.4)$ \\
\hline $\begin{array}{l}\text { Not working (volunteering, retired, sick leave, } \\
\text { homemaker) }\end{array}$ & $166(5 \mathrm{I} .1)$ \\
\hline Student & $53(16.3)$ \\
\hline Not applicable & II (3.4) \\
\hline \multicolumn{2}{|l|}{ Geographical location of residence, $n$ (\%) } \\
\hline Urban & 247 (78.9) \\
\hline Rural & $66(21.1)$ \\
\hline \multicolumn{2}{|c|}{ Disease and disorder-related characteristics of participants } \\
\hline \multicolumn{2}{|c|}{ Musculoskeletal condition, ${ }^{\mathrm{a}} \mathrm{n}(\%)$} \\
\hline Osteoarthritis & $138(42.5)$ \\
\hline Rheumatoid arthritis & $115(35.4)$ \\
\hline Psoriatic arthritis & $21(6.5)$ \\
\hline Lupus or SLE & $9(2.8)$ \\
\hline Gout & $4(1.2)$ \\
\hline Ankylosing spondylitis & $10(3.1)$ \\
\hline Juvenile idiopathic arthritis & $10(3.1)$ \\
\hline Other musculoskeletal problem & $35(10.8)$ \\
\hline Unsure of type/diagnosis & $34(10.5)$ \\
\hline \multicolumn{2}{|l|}{ Musculoskeletal condition (grouped), ${ }^{\mathrm{b}} \mathrm{n}(\%)$} \\
\hline Inflammatory condition & $165(50.8)$ \\
\hline Noninflammatory condition & $102(31.4)$ \\
\hline Other musculoskeletal problem & $16(4.9)$ \\
\hline Unsure of type/diagnosis & $42(12.9)$ \\
\hline \multicolumn{2}{|l|}{ Visit type, $\mathrm{n}(\%)$} \\
\hline Initial visit & $168(53.0)$ \\
\hline Follow-up visit & $149(47.0)$ \\
\hline $\begin{array}{l}\text { Duration of musculoskeletal symptoms } \\
\text { (years), mean (range) }\end{array}$ & $9.70(0-75)$ \\
\hline $\begin{array}{l}\text { Pain, mean }(S D) \\
(0=\text { no pain to } 100=\text { pain as bad as can be })\end{array}$ & $43.50(27.2)$ \\
\hline $\begin{array}{l}\text { Function, mean }(S D) \\
(I=\text { poor to } 5=\text { excellent })\end{array}$ & $2.66(1.1)$ \\
\hline $\begin{array}{l}\text { Self-reported overall health, mean }(S D) \\
\text { (I= poor to } 5=\text { excellent })\end{array}$ & $3.12(1.1)$ \\
\hline
\end{tabular}

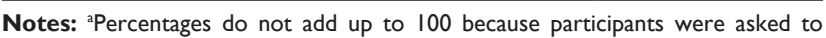
check all that applied; ban additional variable was created to capture the broad disease categories of patients seen by ERPs. Percentage total adds up to 100 . Inflammatory condition: any participant reporting an inflammatory diagnosis (rheumatoid arthritis, psoriatic arthritis, lupus or SLE, gout, ankylosing spondylitis, juvenile idiopathic arthritis). Noninflammatory condition: any participant reporting an osteoarthritis diagnosis and no inflammatory diagnosis. Other musculoskeletal problem: any participant reporting only "other musculoskeletal problem". Unsure of type/diagnosis: any participant reporting only "unsure of type/diagnosis".

Abbreviations: SLE, systemic lupus erythematosus; SD, standard deviation; ERPs, extended-role practitioners. 
initial ( $\mathrm{n}=168,53.0 \%)$ or follow-up ( $\mathrm{n}=149,47.0 \%)$ visit. Demographic and disease-related variables are reported in Table 1.

\section{Patient-Practitioner Interaction Scale}

Mean subscale scores for the PPIS were very high ( $5=$ greater satisfaction): providing information (4.50), rapport (4.63), and meeting patient needs (4.60). Mean item scores for the PPIS ranged from 4.45 to 4.74. Univariate statistics for each subscale are reported in Table 2. The PPIS showed good reliability (internal consistency) across subscales: providing information ( $\alpha=0.89$ ), rapport ( $\alpha=0.87)$, and meeting patient needs $(\alpha=0.84)$.

Table 2 Subscale and item-level scores for the PatientPractitioner Interaction Scale

\begin{tabular}{|c|c|c|c|c|}
\hline \multirow{2}{*}{$\begin{array}{l}\text { Patient-Practitioner } \\
\text { Interaction Scale }\end{array}$} & \multicolumn{4}{|l|}{$n=325$} \\
\hline & $\begin{array}{l}\text { Mean } \\
(\mathrm{SD})\end{array}$ & Median & Mode & Range \\
\hline \multicolumn{5}{|c|}{ Subscale scores (I to 5 [greater satisfaction]) } \\
\hline $\begin{array}{l}\text { Providing information subscale } \\
\text { (mean of items I, 2) }\end{array}$ & $4.5(0.6)$ & 5.0 & 5.0 & $2.5-5.0$ \\
\hline $\begin{array}{l}\text { Rapport subscale (mean of } \\
\text { items 3-8) }\end{array}$ & $4.6(0.5)$ & 5.0 & 5.0 & $3.0-5.0$ \\
\hline $\begin{array}{l}\text { Meeting patient needs subscale } \\
\text { (mean of items 9-II) }\end{array}$ & $4.6(0.5)$ & 5.0 & 5.0 & $2.7-5.0$ \\
\hline \multicolumn{5}{|c|}{ Item scores ( $I=$ strongly disagree to $5=$ strongly agree $)$} \\
\hline $\begin{array}{l}\text { I. The advanced practitioner gave } \\
\text { me the information I needed. }\end{array}$ & $4.5(0.6)$ & 5.0 & 5.0 & $3.0-5.0$ \\
\hline $\begin{array}{l}\text { 2. The advanced practitioner } \\
\text { helped me understand my } \\
\text { condition. }\end{array}$ & $4.5(0.7)$ & 5.0 & 5.0 & $2.0-5.0$ \\
\hline $\begin{array}{l}\text { 3. I feel that I can contact the } \\
\text { advanced practitioner if I } \\
\text { need to. }\end{array}$ & $4.5(0.7)$ & 5.0 & 5.0 & $2.0-5.0$ \\
\hline $\begin{array}{l}\text { 4. I could talk to the advanced } \\
\text { practitioner. }\end{array}$ & $4.6(0.6)$ & 5.0 & 5.0 & $2.0-5.0$ \\
\hline $\begin{array}{l}\text { 5. I would recommend the } \\
\text { advanced practitioner to a } \\
\text { friend. }\end{array}$ & $4.6(0.6)$ & 5.0 & 5.0 & $1.0-5.0$ \\
\hline $\begin{array}{l}\text { 6. The advanced practitioner } \\
\text { was attentive to me. }\end{array}$ & $4.7(0.5)$ & 5.0 & 5.0 & $3.0-5.0$ \\
\hline $\begin{array}{l}\text { 7. The advanced practitioner } \\
\text { was not in a rush. }\end{array}$ & $4.6(0.6)$ & 5.0 & 5.0 & $2.0-5.0$ \\
\hline $\begin{array}{l}\text { 8. The advanced practitioner } \\
\text { was professional. }\end{array}$ & $4.7(0.5)$ & 5.0 & 5.0 & $3.0-5.0$ \\
\hline $\begin{array}{l}\text { 9. The advanced practitioner } \\
\text { explained the reason for } \\
\text { treatment. }\end{array}$ & $4.6(0.6)$ & 5.0 & 5.0 & $2.0-5.0$ \\
\hline 10. My needs were addressed. & $4.6(0.6)$ & 5.0 & 5.0 & $2.0-5.0$ \\
\hline $\begin{array}{l}\text { II. The advanced practitioner } \\
\text { used words I understood. }\end{array}$ & $4.7(0.5)$ & 5.0 & 5.0 & $3.0-5.0$ \\
\hline
\end{tabular}

Abbreviation: SD, standard deviation.

\section{Secondary patient-satisfaction outcomes}

Univariate statistics for secondary patient-satisfaction outcomes are reported in Table 3. Mean scores for all eight service-related items were high ( $5=$ greater satisfaction). Mean scores for the six GHAA CSS items ranged from 4.13 to 4.57. Patients were also highly satisfied with the thoroughness of the physical examination performed by the clinician

Table 3 Item-level scores for secondary patient-satisfaction outcomes

$n=325$

\section{Secondary patient-satisfaction outcomes}

Satisfaction with services received, mean (SD) ( $I=$ strongly disagree to

$5=$ strongly agree)

History taken was thorough and done with competence. ${ }^{\mathrm{a}} \quad 4.57(0.6)$

The physical examination was thorough and done with $4.64(0.5)$

competence.

Results of investigations were well $\quad 4.52(0.7)$

explained.

Diagnosis was well explained. ${ }^{a} \quad 4.44(0.8)$

Opportunity to discuss all questions. ${ }^{a} \quad 4.57(0.6)$

Happy with the answers to my questions. ${ }^{a} \quad 4.55(0.6)$

Recommendations, advice, and suggestions were helpful. ${ }^{a} \quad 4.38(0.7)$

Educational materials provided were useful. ${ }^{\mathrm{a}, \mathrm{b}} \quad 4.13(0.9)$

Satisfaction with wait time, $\mathrm{n}(\%)$

Acceptable wait from referral to appointment

Strongly agree I44 (46.0)

Agree $130(41.5)$

Neither agree nor disagree $\quad 22(7.0)$

Disagree 13 (4.2)

Strongly disagree 4 (I.3)

Acceptable wait in clinic today

Strongly agree $\quad$ I45 (45.9)

Agree 129 (40.8)

Neither agree nor disagree $\quad 19(6.0)$

Disagree $18(5.7)$

Strongly disagree $\quad 5$ (1.6)

Satisfaction with care compared to previous arthritis care received from other health care professionals, $\mathrm{n}(\%)$

More satisfactory $189(61.6)$

Same $\quad 113(36.8)$

Less satisfactory 5 (I.6)

ACPAC program-trained therapist is the most appropriate health care

professional to be seeing me, $\mathrm{n}(\%)$

Strongly agree $\quad$ I47 (46.0)

Agree 125 (39.1)

Neither agree nor disagree $\quad 39$ (I2.2)

Disagree $8(2.5)$

Strongly disagree I (0.3)

Overall satisfaction, mean (SD)

Overall quality of care ( $I=$ poor to $5=$ excellent $) \quad 4.39(0.8)$

Overall coordination of care ( $\mathrm{I}=$ poor to $5=$ excellent $) \quad 4.36(0.8)$

Notes: altems from the Group Health Association of America's Consumer Satisfaction Survey; bnumber of missing responses from item "Educational materials provided were useful": $n=48$ (14.8\%).

Abbreviations: SD, standard deviation; ACPAC, Advanced Clinician Practitioner in Arthritis Care. 
(4.64) and the explanation of investigation results provided to them (4.52).

Eighty-eight percent $(n=274)$ of respondents either strongly agreed or agreed that the length of time from their referral to their appointment was acceptable. Similarly, $87 \%$ $(n=274)$ expressed some level of agreement that their wait time in the clinic was acceptable. In both cases, less than $8 \%$ of patients disagreed or strongly disagreed that their wait time was acceptable. A detailed breakdown of patient responses is included in Table 3.

Over $98 \%$ of patients indicated that the arthritis care provided by their ERP was comparable to $(36.8 \%, \mathrm{n}=113)$ or better than $(61.6 \%, n=189)$ that received from other health care professionals. Less than $2 \%(n=5)$ of patients perceived ERP care provision to be less satisfactory. Eighty-five percent $(n=272)$ of respondents felt that the ACPAC ERP was the most appropriate provider of arthritis care at that point of contact. Overall patient satisfaction with the quality (mean 4.39) and coordination (mean 4.36) of their arthritis care was high.

\section{Areas for improvement and things being done well}

About $25 \%$ of participants provided suggestions to improve the care experience, the thematic analysis of which generated five core themes. Similarly, two-thirds of participants included comments detailing elements of their care with which they were satisfied, analysis of which generated eight major themes. A detailed list of themes is included in Table 4.

For example, one patient who might have benefited from clarification of the ERP role noted that they "thought seeing a physiotherapist would entail some treatment for [their] hand and muscle pain and working to loosen joint stiffness. The entire visit was more like a consultation only".

Also included in participants' recommendations were suggestions for role expansion and raising public awareness about this new role. One participant suggested "[educating] more [ERPs] so they can help patients with their disease", and another recommended "[informing] the public about the availability of these professionals and how they can help sufferers of arthritis".

Importantly, patients often noted the value of ERPs in improving access to care, and were quick to highlight their practitioner's knowledgeable and caring manner:

What an excellent service!! It cuts down on the amount of time you have to wait to learn more about the diagnosis, ways to deal with it, and go for more tests before seeing
Table 4 Participant responses to the open-ended items "Areas for improvement" and "Things being done well" by theme

\begin{tabular}{|c|c|}
\hline Theme & \\
\hline \multicolumn{2}{|l|}{ Areas for improvement } \\
\hline Time & $\begin{array}{l}\text { Unacceptable length of wait; } \\
\text { insufficient time spent with patient }\end{array}$ \\
\hline $\begin{array}{l}\text { Coordination of care and } \\
\text { logistical issues }\end{array}$ & $\begin{array}{l}\text { Desire for improved } \\
\text { communication between } \\
\text { health care providers; improved } \\
\text { access to assistive devices in clinic }\end{array}$ \\
\hline $\begin{array}{l}\text { Information or } \\
\text { educational needs }\end{array}$ & $\begin{array}{l}\text { Desire for different types of } \\
\text { information and educational } \\
\text { materials }\end{array}$ \\
\hline Extended-role suggestions & $\begin{array}{l}\text { Expanded role utilization; clarity } \\
\text { about role }\end{array}$ \\
\hline Patient concerns & $\begin{array}{l}\text { Wanting more time with the } \\
\text { doctor }\end{array}$ \\
\hline \multicolumn{2}{|l|}{ Things being done well } \\
\hline $\begin{array}{l}\text { Positive personal } \\
\text { attributes }\end{array}$ & $\begin{array}{l}\text { Personality, rapport, } \\
\text { comprehensiveness and } \\
\text { competence }\end{array}$ \\
\hline Time & $\begin{array}{l}\text { Reasonable wait, efficiency and } \\
\text { sufficient time for appointment }\end{array}$ \\
\hline Comfort and confidence & $\begin{array}{l}\text { Sense of comfort an trust in the } \\
\text { ERP }\end{array}$ \\
\hline Knowledge and & ERPs thought to be \\
\hline information provision & $\begin{array}{l}\text { knowledgeable; provided } \\
\text { information and education }\end{array}$ \\
\hline Communication & $\begin{array}{l}\text { ERPs exhibit excellent } \\
\text { communication skills }\end{array}$ \\
\hline $\begin{array}{l}\text { Organization and } \\
\text { coordination of care team }\end{array}$ & $\begin{array}{l}\text { Recognition of the fact the ERPs } \\
\text { were part of well-organized } \\
\text { processes and teams }\end{array}$ \\
\hline Availability and access & $\begin{array}{l}\text { Appreciation for timely access } \\
\text { to the practitioner and often the } \\
\text { ability to reach them directly with } \\
\text { questions }\end{array}$ \\
\hline Physical examination & Met approval, gentle \\
\hline
\end{tabular}

Abbreviation: ERP, extended-role practitioner.

the specialist. My advanced practitioner was very patient and knowledgeable in every way.

Another patient wrote:

I am very pleased with the care and support I have received from my practitioner. It is easy to talk with [them] and if [they] don't have an answer to a question [they are] quick to find out for me. [My ERP] makes me feel like I am a person and not just a number in a long line of people. [T] his is a wonderful support system. Thank you.

\section{Discussion}

The goal of this study was to capture patient satisfaction with the arthritis care received from ACPAC program-trained ERPs. Patients were satisfied with the information provided 
to them, the rapport that was developed, and their ERP's ability to meet their health care needs. Patients felt that the time they waited from referral to appointment and in clinic was acceptable. They also felt that the ACPAC ERP was the most appropriate health care professional to be treating them for their MSK-related health problem, and they reported the care they received to be comparable to or better than that previously provided by other clinicians.

The limitations of this study were logistical and measurement-related. Logistical limitations, such as the language of our survey, narrowed our participant pool. Measurement limitations, such as selection bias, have likely skewed the data in our favor, a common and as-yet-unresolved issue in the evaluation of patient satisfaction. ${ }^{5}$

The study questionnaire was not created for use in children, making it cumbersome to issue in this population. Additionally, the inclusion criteria of the study disqualified patients who did not interact with their ACPAC programtrained clinician face to face and those who could not complete the survey in English. These criteria may have excluded potential participants at any of the 15 participating institutions. These exclusions are unfortunate, because the ACPAC program graduates, through the implementation of new models of care and deployment in underserviced areas, currently provide care and education to varied ethnic, cultural, and geographical populations through different modalities.

In a limited number of instances, ERPs gave survey packages to their patients. Every effort was made to ensure that a clinic administrator gave the study package to potential participants. However, as a result of clinic organization, staffing issues, and home visits, recruitment by graduates was unavoidable in some cases. Knowing that this might be a concern at certain institutions, survey packages were provided to each practice in sealed envelopes. Patients were asked to decide whether or not they wished to participate after leaving the clinic. They were also advised not to share their decision to participate with their clinician, and if they chose not to participate, they were asked to discard the survey package after leaving the clinic. All possible efforts were made to avoid undue pressure to participate, as well as any associated response bias.

The measurement limitations of this study include those common to most patient-satisfaction studies: they are selection bias, acquiescence bias, and high undifferentiated levels of satisfaction. ${ }^{17}$ The variety of constructs and question types included in this study captured a wealth of valuable information, including patient-generated suggestions for the improvement of care as it relates to the presence of an ACPAC ERP.

Of note, we did not include a comparison group in this study. Given the breadth of the roles assumed by ACPAC ERPs, it was not feasible to include a comparison group. There is no consistent comparator, such a physician specialist or nurse practitioner, common to all 27 roles, geographical settings, or models of care.

Finally, a large number of missing responses (14.8\%, $\mathrm{n}=48$ ) to the GHAA CSS item "Educational materials provided were useful" suggests that further assessment of the provision of educational materials by ERPs may be necessary. Acknowledging the variation among roles, we recognize that this question may not be relevant to all patient-ERP interactions (eg, follow-up visits with long-term patients).

It is a strength of this study that the patient populations of all practicing ACPAC ERPs were included, considering the broad spectrum of clinical care environments in which dedicated arthritis care is provided by ACPAC ERPs.

Our analyses included a large sample of participants. We are pleased with our response rate $(46.8 \%)$, particularly considering that no reminder calls, replacement questionnaires, or incentives were included in our study design and the fact that our study population had a higher-than-normal chance of experiencing writing difficulties due to MSK conditions.

The survey content was comprehensive. It included a simple yet broad measure of patients' satisfaction with their clinician interaction, supplemented by additional satisfaction items related to relevant aspects of the patient care experience, as suggested by Hudak and Wright. ${ }^{17}$ In addition, by giving patients the opportunity to detail strengths and areas for improvement, this study captured a wealth of new information that would otherwise have gone undetected. Hudak and Wright ${ }^{17}$ noted that there can be a discrepancy between the findings of qualitative and quantitative measures of patient satisfaction, ${ }^{24,25}$ and Dougall et $\mathrm{al}^{25}$ suggested that the use of standardized measures alone is insufficient. Qualitative findings from this study will be used for quality-assurance purposes in the ongoing improvement of the ACPAC program, and the growth and development of ERP roles.

In addition to collecting comprehensive satisfaction data, we evaluated the reliability of the PPIS, which showed good internal consistency across subscales, indicating that it is a reliable measure of patient satisfaction for use in this population.

Because the present study is just one component of a larger system-level evaluation, it contributes valuable information to a growing body of knowledge that supports 
the training and deployment of ACPAC ERPs. Focusing on the patient perspective, this work captures the perceptions and suggestions of a key stakeholder in the development of extended-practice roles in arthritis care. We know that there is far more to positive health-related outcomes than "effective" treatments. Our findings suggest that patients' high satisfaction with their ERP may, in concert with other factors, impact positive health-related behaviors and treatment outcomes.

In a recent review of the literature evaluating the impact of variably trained extended-practice physical therapists on patients with MSK conditions, Desmeules et $\mathrm{al}^{26}$ identified seven studies assessing patient satisfaction with care received. ${ }^{27-33}$ These included studies conducted in a variety of clinical settings in Canada, the UK, and Australia evaluating ERP roles ranging from triage to primary care to independent management. Represented patient populations included individuals with general MSK complaints, those with peripheral MSK injuries, postsurgical patients, and pediatric inflammatory patients. Three of these studies comparing usual care with services provided by ERPs found significant differences in patient satisfaction favoring ERPs. ${ }^{28,30,31}$ Three other studies found no such difference, ${ }^{27,29,33}$ suggesting similar levels of patient satisfaction with usual care and ERP services. Patient satisfaction with MSK-related care provided by ERPs was high in all seven studies.

Additional studies, which did not meet the inclusion criteria for the aforementioned review, have also reported high percentages of patients satisfied with ERP services. ${ }^{34-37}$ All conducted in the UK, three studies reported that $89 \%$ of patients were satisfied with services provided by ERPs in orthopedic outpatient clinics. ${ }^{34,35,37}$ One study evaluating an ERP-led, community-based back pain-management program (management activities included both ERPs and general practitioners with special interests) reported that $88 \%$ of patients rated the service provided as excellent or good. ${ }^{36}$

These studies evaluated the impact of individual or small groups of ERPs in specific settings, and reported very positive patient perceptions of the care they received. The present study supports these findings and broadens the scope of the ERP literature by specifically evaluating patients' satisfaction with the care provided by ACPAC ERPs, clinicians formally trained and rigorously evaluated to ensure their competency in arthritis care.

Future studies evaluating the impact of ACPAC program-trained clinicians at the patient level should focus on health-related behaviors and treatment outcomes, as well as the relationship between patient satisfaction and these two outcomes. Future work could also compare, within context-controlled environments, the arthritis care provided by ERPs benchmarked against other health care practitioners. Patient-informed quality-improvement work should also be conducted to refine and advance the new models of care and novel roles developed by individual ACPAC ERPs. The financial impact of these roles should also be evaluated.

Based on our findings, both adult and pediatric patients with varied diagnoses in a variety of clinical settings were very satisfied with the care they receive from ACPAC program-trained clinicians. The ACPAC program graduates were viewed as knowledgeable and competent, and their roles and unique models of care are being accepted by patients as valuable and effective health care options, making them an asset to the future of arthritis care.

In conclusion, patients were comfortable with and felt well cared for by the ACPAC program-trained ERPs. Patients found wait times associated with care provided by ERPs to be acceptable, and were satisfied with the quality of care received. Importantly, patients felt that ACPAC ERPs were able to provide competent care that was comparable to or better than that afforded by other health care providers.

\section{Acknowledgments}

We wish to thank the Mobility Program Clinical Research Unit, the ACPAC ERPs, their clinical administrative staff, and our participants for their respective contributions to this study. This project was supported by a Ministry of Health and Long-Term Care HealthForce Ontario Grant.

\section{Disclosure}

The authors report no conflicts of interest in this work.

\section{References}

1. MacKay C, Devitt R, Soever L, Badley E. An Exploration of Comprehensive Interdisciplinary Models for Arthritis. Toronto: University Health Network and The Arthritis Society; 2005.

2. MacKay C, Veinot P, Badley E. An Overview of Developments in Comprehensive Interdisciplinary Models of Care for Arthritis: Provider and Patient Perspectives. Toronto: University Health Network and The Arthritis Society; 2006.

3. Pascoe GC. Patient satisfaction in primary health care: a literature review and analysis. Eval Program Plann. 1983;6(3-4):185-210.

4. Aharony L, Strasser S. Patient satisfaction: what we know about and what we still need to explore. Med Care Rev. 1993;50(1):49-79.

5. Carr-Hill RA. The measurement of patient satisfaction. J Public Health Med. 1992;14(3):236-249.

6. Guldvog B. Can patient satisfaction improve health among patients with angina pectoris? Int J Qual Health Care. 1999;11(3):233-240.

7. Hurwitz EL, Morgenstern H, Yu F. Satisfaction as a predictor of clinical outcomes among chiropractic and medical patients enrolled in the UCLA Low Back Pain Study. Spine. 2005;30(19):2121-2128. 
8. Jackson JL. Communication about symptoms in primary care: impact on patient outcomes. J Altern Complement Med. 2005;11 Suppl 1: S51-S56.

9. Zhang Z, Gerstein DR, Friedmann PD. Patient satisfaction and sustained outcomes of drug abuse treatment. J Health Psychol. 2008;13(3): 388-400.

10. Hanly JG. Manpower in Canadian academic rheumatology units: current status and future trends. Canadian Council of Academic Rheumatologists. J Rheumatol. 2001;28(9):1944-1951.

11. Lineker SC, Lundon K, Shupak R, Schneider R, MacKay C, Varatharasan N. Arthritis extended-role practitioners: impact on community practice (an exploratory study). Physiother Can. 2011;63(4): 434-442.

12. Lundon K, Shupak R, Sunstrum-Mann L, Galet D, Schneider R. Leading change in the transformation of arthritis care: development of an interprofessional academic-clinical education training model. Healthc $Q$. 2008;11(3):62-68.

13. Lundon K, Shupak R, Schneider R, Herold MJ. Development and early evaluation of an inter-professional post-licensure education programme for extended practice roles in arthritis care. Physiother Can. 2011;63(1):94-103.

14. Kaplan R, Norton D. The Balanced Scorecard: Translating Strategy into Action. Boston: Harvard Business School Press; 1996.

15. Cott C, Jaglal S, McKillop I, et al. Hospital Report 2005: Rehabilitation. Toronto: Hospital Report Research Collaborative, University of Toronto; 2005.

16. Passalent L, Kennedy C, Soever L, et al. System integration and clinical utilization of the Advanced Clinician Practitioner in Arthritis Care (ACPAC) program-trained extended role practitioners in Ontario: a two-year, system-level evaluation. Healthc Policy. 2013;8(4):56-70.

17. Hudak PL, Wright JG. The characteristics of patient satisfaction measures. Spine (Phila Pa 1976). 2000;25(24):3167-3177.

18. Smith JK, Falvo D, McKillip J, Pitz G. Measuring patient perceptions of the patient-doctor interaction. Development of the PDIS. Eval Health Prof. 1984;7(1):77-94.

19. Falvo DR, Smith JK. Assessing residents' behavioral science skills: patients' views of physician-patient interaction. J Fam Pract. 1983;17(3):479-483.

20. Taenzer P, Bultz BD, Carlson LE, et al. Impact of computerized quality of life screening on physician behaviour and patient satisfaction in lung cancer outpatients. Psychooncology. 2000;9(3):203-213.

21. Davies AR, Ware JE. GHAA's Consumer Satisfaction Survey and User's Manual. 2nd ed. Washington: GHAA; 1991

22. Ware JE Jr, Hays RD. Methods for measuring patient satisfaction with specific medical encounters. Med Care. 1988;26(4):393-402.

23. Ferraz MB, Quaresma MR, Aquino LR, Atra E, Tugwell P, Goldsmith CH. Reliability of pain scales in the assessment of literate and illiterate patients with rheumatoid arthritis. J Rheumatol. 1990;17(8): 1022-1024.
24. Williams B, Coyle J, Healy D. The meaning of patient satisfaction: an explanation of high reported levels. Soc Sci Med. 1998;47(9): 1351-1359.

25. Dougall A, Russell A, Rubin G, Ling J. Rethinking patient satisfaction: patient experiences of an open access flexible sigmoidoscopy service. Soc Sci Med. 2000;50(1):53-62.

26. Desmeules F, Roy JS, MacDermid JC, Champagne F, Hinse O, Woodhouse LJ. Advanced practice physiotherapy in patients with musculoskeletal disorders: a systematic review. BMC Musculoskelet Disord. 2012;13:107.

27. Campos AA, Graveline C, Ferguson J, Feldman BM, Shneider R, Laxer RM. The physical therapy practitioner (PTP) on pediatric rheumatology: high level of patient and parent satisfaction with services. Physiother Can. 2002;54(1):32-36.

28. Daker-White G, Carr AJ, Harvey I, et al. A randomised controlled trial. Shifting boundaries of doctors and physiotherapists in orthopaedic outpatient departments. J Epidemiol Community Health. 1999;53(10): 643-650.

29. Kennedy DM, Robarts S, Woodhouse L. Patients are satisfied with advanced practice physiotherapists in a role traditionally performed by orthopaedic surgeons. Physiother Can. 2010;62(4):298-305.

30. McClellan CM, Greenwood R, Benger JR. Effect of an extended scope physiotherapy service on patient satisfaction and the outcome of soft tissue injuries in an adult emergency department. Emerg Med J 2006;23(5):384-387.

31. Richardson B, Shepstone L, Poland F, Mugford M, Finlayson B, Clemence N. Randomised controlled trial and cost consequences study comparing initial physiotherapy assessment and management with routine practice for selected patients in an accident and emergency department of an acute hospital. Emerg Med J. 2005;22(2):87-92.

32. Sephton R, Hough E, Roberts SA, Oldham J. Evaluation of a primary care musculoskeletal clinical assessment service: a preliminary study. Physiotherapy. 2010;96(4):296-302.

33. Taylor NF, Norman E, Roddy L, Tang C, Pagram A, Hearn K. Primary contact physiotherapy in emergency departments can reduce length of stay for patients with peripheral musculoskeletal injuries compared with secondary contact physiotherapy: a prospective non-randomised controlled trial. Physiotherapy. 2011;97(2):107-114.

34. Byles SE, Ling RS. Orthopaedic out-patients - a fresh approach. Physiotherapy. 1989;75(7):435-437.

35. Hockin J, Bannister G. The extended role of a physiotherapist in an out-patient orthopaedic clinic. Physiotherapy. 1994;80(5):281-284.

36. Maddison P, Jones J, Breslin A, et al. Improved access and targeting of musculoskeletal services in northwest Wales: Targeted Early Access to Musculoskeletal Services (TEAMS) programme. BMJ. 2004;329(7478): 1325-1327.

37. Pearse EO, Maclean A, Ricketts DM. The extended scope physiotherapist in orthopaedic out-patients - an audit. Ann R Coll Surg Engl. 2006;88(7):653-655.
Open Access Rheumatology Research and Reviews

\section{Publish your work in this journal}

Open Access Rheumatology Research and Reviews is an international, peer-reviewed, open access journal, publishing all aspects of clinical and experimental rheumatology in the clinic and laboratory including the following topics: Pathology, pathophysiology of rheumatological diseases; Investigation, treatment and management of rheumatological

\section{Dovepress}

diseases; Clinical trials and novel pharmacological approaches for the treatment of rheumatological disorders. The manuscript management system is completely online and includes a very quick and fair peerreview system, which is all easy to use. Visit http://www.dovepress.com/ testimonials.php to read real quotes from published authors. 